\title{
Relationship between dentition, anthropometric measurements, and metabolic syndrome in the elderly
}

\author{
Relação entre dentição, medidas antropométricas e síndrome metabólica em idosos

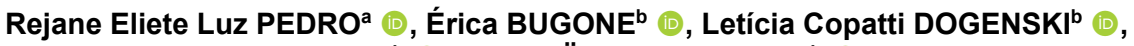 \\ Moisés Zacarias CARDOSO ${ }^{b}$ (1), Aline HÜBNER DA SILVA ${ }^{b}$ (D), Maria Salete Sandini LINDEN ${ }^{b}$ (D), \\ João Paulo DE CARLI ${ }^{b^{*}}$ (1), Eduardo José VALDEZ ${ }^{a}$ (1) \\ aPUCRS - Pontíficia Universidade Católica do Rio Grande do Sul, Departamento de Gerodontologia, Porto Alegre, \\ RS, Brasil \\ bUPF - Universidade de Passo Fundo, Departamento de Odontologia, Passo Fundo, RS, Brasil
}

\begin{abstract}
How to cite: Pedro REL, Bugone E, Dogenski LC, Cardoso MZ, Hübner da Silva A, Linden MSS, De Carli JP, Valdez EJ. Relationship between dentition, anthropometric measurements, and metabolic syndrome in the elderly. Rev Odontol UNESP. 2019;48:e20190021. https://doi.org/10.1590/1807-2577.02119
\end{abstract}

\begin{abstract}
Resumo
Introdução: A perda dentária é um distúrbio de saúde dos idosos que pode levar à deficiência mastigatória e riscos nutricionais, induzindo alterações bioquímicas da síndrome metabólica (SM). Objetivo: Verificar a relação entre número de dentes, medidas antropométricas e SM em um grupo de idosos. Material e método: 0 estudo foi desenvolvido na cidade de Porto Alegre, RS, Brasil, e foi dividido em três fases. A primeira fase coletou informações do banco de dados de todos os participantes do projeto e a segunda coletou dados sociodemográficos, antropométricos e bioquímicos. A terceira fase foi dividida em duas outras fases: primeiro foram aplicadas entrevistas de saúde bucal aos idosos (281 pacientes avaliados por ligações telefônicas e 23 atendidos em domićlio) e, segundo, 45 pacientes foram selecionados aleatoriamente e convidados a validar os dados obtidos por telefone com exames clínicos orais. A amostra foi composta por 304 indivíduos. Os dados coletados foram tabulados e analisados por meio de testes estatísticos. Resultado: Mulheres idosas com perda dentária severa apresentam um risco significativamente maior de desenvolver SM. Assim, a manutenção dos dentes naturais nos idosos é um fator protetor para a síndrome. Conclusão: Os achados reforçam a hipótese de que a saúde bucal dos indivíduos, expressa pelo número de dentes, pode comprometer e aumentar o risco de SM em idosos.
\end{abstract}

Descritores: Estudo epidemiológico; envelhecimento; saúde oral; antropometria; síndrome metabólica.

\begin{abstract}
Introduction: Tooth loss is a health disorder of the elderly population that may lead to masticatory deficiency and nutritional risks, inducing the biochemical changes of metabolic syndrome (MS). Objective: To verify the relationship among number of teeth, anthropometric measurements, and MS in a group of elderly people. Material and method: The study was developed in Porto Alegre, RS, Brazil, and it was divided into three phases. The first phase collected information from the database of all project participants and the second one collected sociodemographic, anthropometric, and biochemical data. The third phase was divided into two other phases: first, oral health interviews were applied to the elderly (281 patients evaluated by telephone and 23 visited at home) and second, 45 patients were randomly selected and invited to validate the data obtained by telephone with oral clinical examinations performed by a trained dental surgeon. The sample consisted of 304 individuals. The data collected were tabulated and analyzed using statistical tests. Result: Elderly women with severe tooth loss present a significantly higher risk of developing MS. Thus, the maintenance of natural teeth in the elderly is a protective factor for the syndrome. Conclusion: The findings support the hypothesis that the oral health of individuals, expressed by the number of teeth, may compromise and increase the risk of MS in the elderly.
\end{abstract}

Descriptors: Epidemiological study; aging; oral health; anthropometry; metabolic syndrome. 


\section{INTRODUCTION}

Changes in the socioeconomic conditions, health, and age structure of the population are reflected by the increased rate of elderly people, causing repercussions for both society and the health system. According to population projections of the United Nations in 2015, the total population of Brazil in the age group of 60 years was $11.7 \%$. Population aging is a public health problem that requires planning public policies and directing multi-professional teams to meet such demand ${ }^{1,2}$. Aging may be characterized by morphological, functional, biochemical, and psychological changes that determine the progressive loss of adaptability to the environment, leading to increased susceptibility and vulnerability to a number of diseases, such as metabolic syndrome (MS) ${ }^{3}$.

The MS is a significant public health problem due to its high prevalence rates ${ }^{4}$ and it consists of the association of systemic arterial hypertension, abdominal obesity, glucose intolerance, hypertriglyceridemia, and low blood concentrations of HDL cholesterol. It also presents prothrombotic and pro-inflammatory states and increased levels of circulating cytokines such as C-reactive protein, tumor necrosis factor, and interleukin 65 . The MS is a major risk factor for developing cardiovascular diseases. Multiple meta-analyses have calculated that MS is associated with a 2 -fold increase in cardiovascular outcomes and a 1.5-fold increase in all-cause mortality6.

Confirming the diagnosis of MS according to the criteria from the National Cholesterol Education Program - Adult Treatment Panel (NCEP-ATP III) and identifying risk factors require clinical history, physical examination, and laboratory tests such as fasting blood glucose, HDL cholesterol, triglycerides, and others ${ }^{4}$. The risk factors of MS are related to central fat deposition, insulin resistance, sedentary lifestyle, aging, hormonal imbalance, and genetic predisposition, with the majority of cases of MS occurring in overweight individuals ${ }^{7}$. It is established that obesity and overweight are an increasing global problem with high rates in developed and developing countries ${ }^{8}$.

Anthropometric measurements are used often to evaluate body fat, due to its practicality and low cost. The body mass index (BMI) is the result of the ratio between two anthropometric measurements - waist circumference (WC) and waist/hip ratio (WHR) -, which may estimate indirectly the intra-abdominal fat reflecting the mass of visceral adipose tissue that produces insulin resistance. These measurements are predictive of metabolic disorders, cardiovascular disease, and death ${ }^{9}$. Body fat excess also leads to the accumulation of lipids in tissues, notably in the adipose tissue, muscles, liver, and pancreatic $\beta$-cells, which seem to induce the biochemical changes in $\mathrm{MS}^{10}$.

Another common problem in the elderly is poor oral health and, from the oral problems of such patients, edentulism is one of the most frequent. The loss of permanent dentition affects chewing and consequently digestion. It also affects pronunciation and aesthetics, changing food selection and preparation, which leads individuals to eat more easily chewable foods of pasty consistency and rich in carbohydrates ${ }^{11}$. The risk factors of edentulism are smoking, alcohol use, and unhealthy carbohydrate-rich dietary behaviors, which conditions are highly prevalent or increasing at rapid rates in low- and middle-income countries. Apart from these individual factors, edentulism is also strongly associated with lack or limited access to dental care and fluoridated water and higher income inequalities ${ }^{12}$.

An assumed link between periodontal and systemic diseases may be related to shared risk factors, including predisposing genetic variants, health behavior factors such as smoking and dietary habits, physical exercises, and socioeconomic factors. However, pathogenic factors such as the systemic release of periodontal bacteria, release of inflammatory cytokines by periodontal or adipose tissues, oxidative stress, proatherogenic lipoproteins, abdominal obesity, among others may also be responsible for such associations ${ }^{13}$. 
Studies have been suggesting an association between periodontal disease and the components of MS. Periodontitis and MS are multifactorial diseases that share a common inflammatory pathway. Many people with MS have low-grade systemic inflammation, which is reported by high levels of inflammatory mediators such as C-reactive protein (CRP), interleukin-6 (IL-6), and tumor necrotic factor- $\alpha$ (TNF- $\alpha)^{14}$. Therefore, evidence indicates a potential relationship among number of teeth, chewing ability, and nutritional and dietary aspects such as anthropometric profile and MS. This study aimed to determine the relationship between number of teeth, anthropometric measurements, and metabolic syndrome in elderly people from Porto Alegre, RS, Brazil.

\section{MATERIAL AND METHOD}

\section{Ethical Issues, Study Design, and Sample}

The Research Ethics Committee of the Pontifical Catholic University of Rio Grande do Sul (PUCRS) approved the execution of this investigation (opinion n. 07/03869) prior to its initiation. The present study was developed in the city of Porto Alegre, RS, Brazil, at the Institute of Geriatrics and Gerontology of PUCRS, with participants from the Multidimensional Project of the Elderly in Porto Alegre. The objective was to verify the relationship among dentition, anthropometric measurements, and MS in a group of elderly individuals. It is a quantitative, cross-sectional, analytical, and observational study divided into three phases. The first phase was database selection (composed of 1078 individuals), the second was the collection of sociodemographic, anthropometric, and biochemical data of the individuals attending this phase $(\mathrm{n}=511)$. The third phase was divided into two: first, oral health interviews were applied to the elderly $(n=281)$ and second, some patients were randomly selected and invited to validate the data obtained by telephone with clinical oral examinations $(n=23)$. A convenience sample was set up and only individuals selected in the first phase and who participated in the second phase were included in the study. All patients selected in the first phase who did not attend the second one were excluded from the study. The participants with incomplete data in the database were also excluded.

\section{Data Collection}

The data was collected in three phases. In the first phase, the present study used the database of the Multidimensional Project of the Elderly in Porto Alegre 1995-2005, which evaluated 1078 individuals. The second phase included 511 elderly from the 1078 included in the database of the same project. The data were collected only from the 511 individuals who attended the second phase of the study. Sociodemographic, anthropometric, and biochemical data (blood glucose, cholesterol, blood pressure, medication, and others) were collected. This information was provided by the Physical Education, Pharmacy, Medicine, and Nursing schools of PUCRS, which participated in the data collection at this stage.

The data used in the present study, retrieved from the second phase of the study, were the following: Anthropometry: 1) Weight and height - the volunteer was measured with a stadiometer, in a standing position, barefoot, and with minimal clothing. Men were shirtless and women wore light clothing. 2) Perimetry - this study measured only waist and hip circumferences. The waist/hip ratio (WHR) is a fast and easy parallel tool that is very effective in identifying people with high health risks due to abdominal fat. The WHR is the waist circumference divided by the hip circumference. 3) Metabolic syndrome (MS) - the variables for MS characterization are those recommended by the I Brazilian Guideline for Diagnosis and Treatment of Metabolic Syndrome (2005). Thus, the components of the NCEP-ATP III for obesity 
by abdominal circumference were stipulated in greater than $102 \mathrm{~cm}$ for men and greater than $88 \mathrm{~cm}$ for women, triglycerides equal to or greater than $150 \mathrm{mg} / \mathrm{dL}$, and HDL cholesterol lower than $40 \mathrm{mg} / \mathrm{dL}$ for men and lower than $50 \mathrm{mg} / \mathrm{dL}$ for women. Additionally, systolic blood pressure should already be equal to or greater than $130 \mathrm{mmHg}$ and diastolic blood pressure equal to or greater than $85 \mathrm{mmHg}$. Finally, fasting glycemia should be equal to or greater than $110 \mathrm{mg} / \mathrm{dL}$. Participants with MS presented three of the five components mentioned above.

In the third stage, the data was collected at two different times. The first phase was performed in the months of January, February, March, April, and May 2008 and the second phase in June 2008.

First phase: Oral health interview applied to the elderly. From the 511 elderly participants of the second phase of the study, 281 were interviewed by telephone and 23 were interviewed in person. However, 191 were not located and 16 had died. In the database of 511 elderly people participating in the second phase of the survey, which collected the address and phone number of the participants, five participants were interviewed during the first five months of 2008 (pilot study). Through a telephone call, the interviewer reminded the elderly people as participants in Project Porto Alegre and asked if they agreed to participate in the survey. Two hundred and eighty-one elderly individuals were interviewed via landline or mobile phone. After collecting the addresses of the individuals, it was decided that 60 elderly people would be visited in their homes to gather more participants, which resulted in 23 elderly people located and interviewed. From all the elderly people whose contacts were obtained, 16 had died. Thus, out of a total sample of 511 elderly people, 191 were not located by any of the methods used. With the exception of the 23 participants interviewed in person, 281 elderly people were interviewed by telephone. They were questioned on the number of teeth, whether they wore total or partial prostheses (upper and lower), whether they were satisfied with the chewing ability and appearance of their teeth, and whether some medication had changed since the first data collection in the second phase of the "Multidimensional Project of the Elderly in Porto Alegre". The last question aimed to identify the elderly person willing to visit the Institute of Geriatrics and Gerontology of PUCRS (IGG) for a clinical dental examination.

Second phase: Study for validating the data obtained by telephone. During the month of June 2008 , a clinical oral examination was performed to validate the data obtained in the interview. From the 281 elderly people interviewed by telephone, 45 participants were randomly selected and invited to attend the Institute of Geriatrics and Gerontology for a dental clinical examination. The questionnaire was identical to the one used in the first phase. A trained dental surgeon performed the oral examination in a non-dental chair, under natural light. The examination consisted of counting the number of teeth in the oral cavity (full teeth restored or not, with or without single prosthesis), verifying the use of prostheses such as upper or lower and partial or total, and questions on chewing satisfaction and appearance of teeth. During the oral examination, neither the participant nor the examiner had access to the results obtained in the telephone interview.

\section{Statistical Analysis}

The data were analyzed through descriptive and inferential statistics using the statistical package SPSS (Statistical Package for the Social Sciences) for Windows, version 11.5. Initially the statistical Kappa was used to test the agreement of the dental data obtained by the questionnaire applied and the dental examination performed. Mean age, body mass index (BMI), and number of teeth were compared among the individuals with and without criteria for MS by Student's t-test. The chi-square test analyzed the association of the prevalence of dental prostheses, chewing satisfaction, and appearance of teeth with the presence of MS. The number of teeth was dichotomized according to the distribution observed for the number of teeth of the 
population interviewed. The BMI was categorized by the level of obesity and its association with the number of teeth, also tested by the chi-square test. Finally, logistic regression tested the risk of presenting MS in a multivariate analysis with all dental parameters. All tests with significance level lower than $5 \%$ were considered statistically significant.

\section{RESULT}

Figure 1 shows the distribution of the number of elderly people interviewed by age group and sex. Most of the 304 respondents were women (219 or 72\%), while 85 (28\%) were men. In the observation of the age groups with 5-year intervals up to 90 years old, all age groups and women were more prevalent. The most prevalent age group was 65 to 69 years old, followed by 70 to 74 years, and lastly the elderly between 75 and 79 years old.

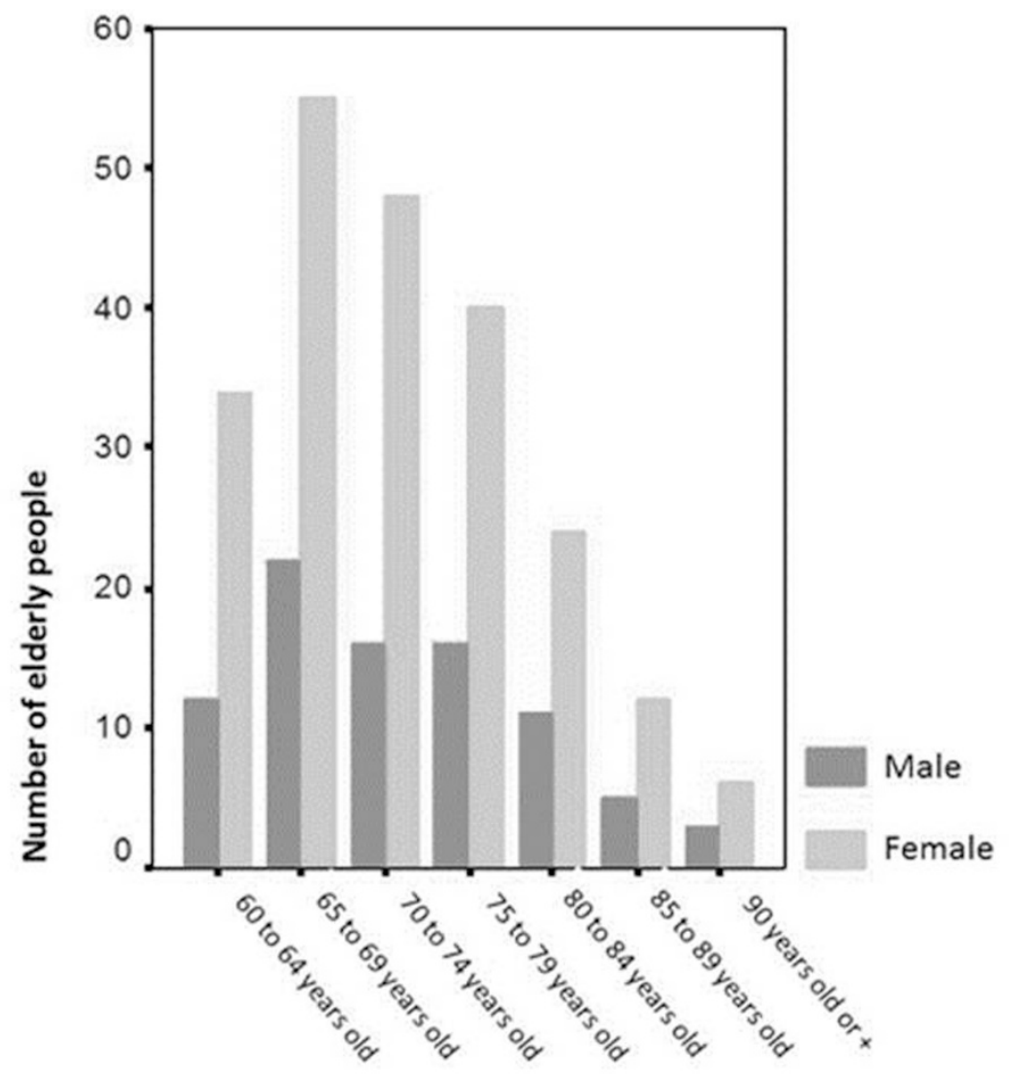

Figure 1. Distribution of the number of elderly people interviewed by age group and sex.

\section{Results of the Oral Health Evaluation of the 304 Respondents}

Regarding the distribution of the number of teeth referred by telephone interview, from the 304 respondents, 91 elderly were edentulous. From these, four people did not have and did not wear total or partial prostheses, 13 people wore only upper prostheses, none of the elderly wore only lower total prosthesis, while the remaining 74 wore upper or lower total prostheses, showing that most edentulous people were rehabilitated with prosthesis.

The elderly were classified in two blocks according to the number of teeth, one with 0 to 9 teeth and the other with 10 or more teeth, according to Figure 2, which also shows the distribution by age group with 5-year intervals up to 90 years old. The number of teeth was 
dichotomized according to the distribution observed for the number of teeth of the population interviewed ${ }^{12}$. Using this criterion, 166 from the 304 respondents had 0 to 9 teeth and 138 had 10 or more teeth. Most elderly people presented less than 10 teeth in the oral cavity, except for the first two age groups. The age group of the majority of the elderly with 0 to 9 teeth was 70 to 74 years, followed by those aged 75 to 79 years and 65 to 69 years.

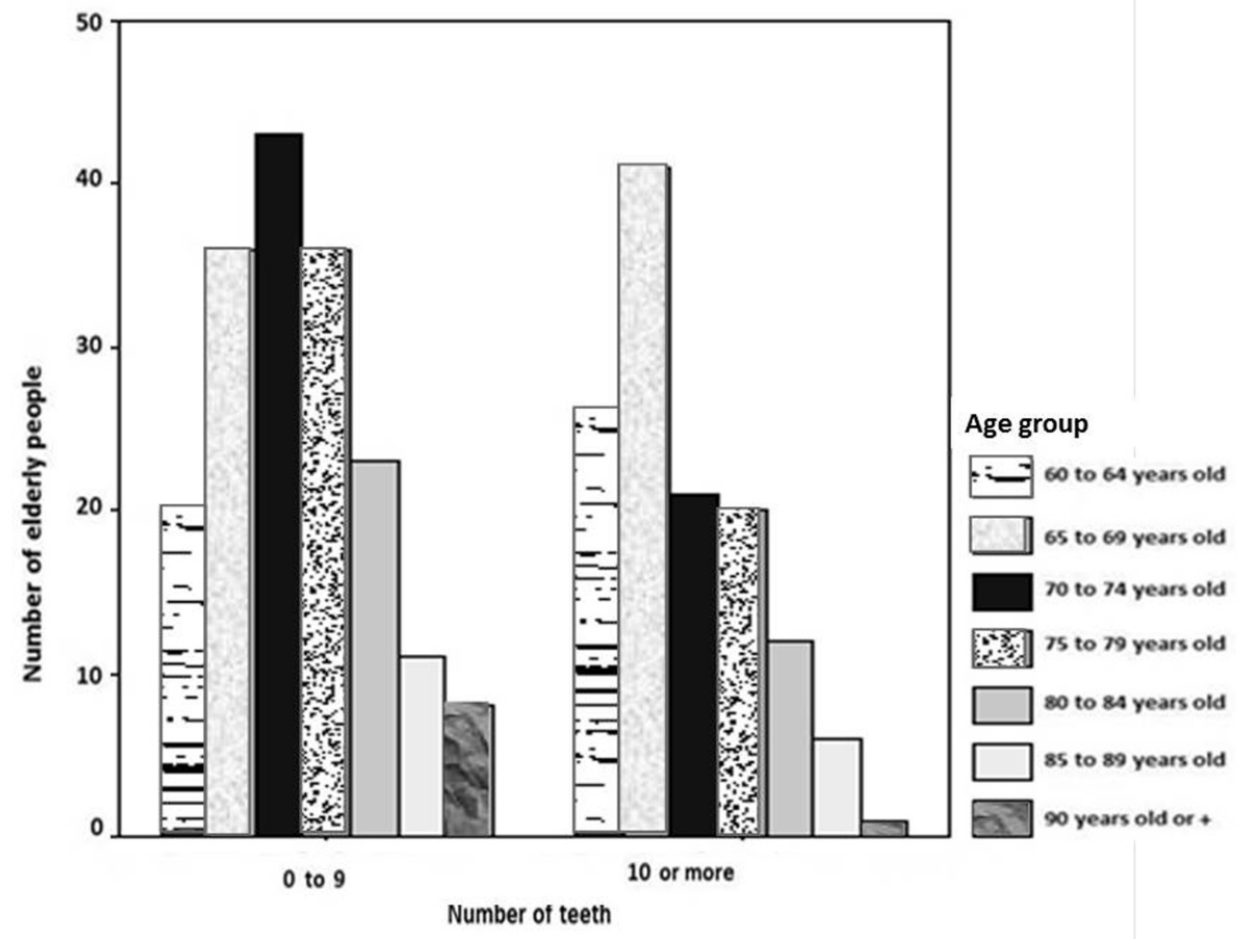

Figure 2. Relationship between age group and number of teeth.

\section{Validation of the Data Obtained in the Interview}

To validate the data obtained in the interview, a clinical examination of $15 \%$ of the sample was performed ${ }^{4}$. The agreement of number of teeth and use of prosthesis measured was almost perfect. For the number of teeth, agreement was $86.6 \%$, for upper prosthesis, it was $95.5 \%$, total lower prosthesis had 94.9\%, partial prosthesis had 94.9\%, and lower partial prosthesis had $84.7 \%$.

The validation regarding satisfaction with chewing and appearance of teeth resulted in substantial agreement, showing $78 \%$ for satisfaction with chewing and $68.7 \%$ for satisfaction with appearance of teeth.

\section{Metabolic Syndrome and Teeth}

From the 304 participants, 266 presented biochemical and anthropometric data required to assess the presence or absence of metabolic syndrome (MS), with three or more positive or negative parameters. From these, 159 elderly people (52.3\%) were classified with MS according to the NCEP-ATP III criteria, while $38(12.5 \%)$ did not present all the data required to verify the presence or absence of MS. The participants with incomplete data were excluded from the subsequent analyses. There were 121 elderly women with MS, from which the majority of $84(69.4 \%)$ had less than 10 teeth in the oral cavity, while the remaining 37 women $(30.6 \%)$ had 
10 or more teeth. For the elderly men, 38 of them presented criteria for MS, from which the majority of $21(55.3 \%)$ had 10 or more teeth in the oral cavity and $17(44.7 \%)$ had less than 10 teeth in the oral cavity. It was observed, therefore, that women with MS represented a greater majority than men in the group with low number of teeth. The mean number of teeth in the group with MS was 8.7 and the mean number of people without MS was 10.6 teeth, meaning that the elderly with a greater number of teeth had lower prevalence of MS.

Chart 1 shows the averages of age and distribution of participants regarding sex, dental data, and classification criteria in relation to MS. From the 266 patients studied for MS, the mean age of individuals with the syndrome was $73.0 \pm 7.88$ years and those without the syndrome were aged $71.8 \pm 7.56$ years. In addition, 69.9\% (186) were women and 30.1\% (80) were men, 139 elderly $(52.3 \%)$ wore upper total prosthesis, 69 (25.9\%) wore lower total prosthesis, $74(27.8 \%)$ wore upper partial prosthesis, and 82 (30.8\%) wore lower partial prosthesis. The largest number of total prostheses was located in the upper arch, while the largest number of partial prostheses was located in the lower arch.

Chart 1. Average age and distribution of participants regarding sex, dental data, and classification criteria in relation to the metabolic syndrome

\begin{tabular}{|c|c|c|c|c|}
\hline & \multicolumn{3}{|c|}{ Metabolic syndrome } & \multirow{2}{*}{ Total n (\%) } \\
\hline & YES n (\%) & NO n (\%) & $\mathbf{P}$ & \\
\hline Age (mean, SD) & $73.0 \pm 7.88$ & $71.8 \pm 7.56$ & 0.195 & \\
\hline $\begin{array}{l}\text { Sex } \\
\text { Female } \\
\text { Male } \\
\end{array}$ & $\begin{array}{l}121(65.1) \\
38(47.5)\end{array}$ & $\begin{array}{l}65(34.9) \\
42(52.5)\end{array}$ & 0.009 & $\begin{array}{c}186(69.9) \\
80(30.1)\end{array}$ \\
\hline Upper total prosthesis & $85(61.2)$ & $54(38.8)$ & 0.632 & $139(52.3)$ \\
\hline Lower total prosthesis & $47(68.1)$ & $22(31.9)$ & 0.101 & $69(25.9)$ \\
\hline Upper partial prosthesis & $45(60.8)$ & $29(39.2)$ & 0.831 & $74(27.8)$ \\
\hline Lower partial prosthesis & $46(56.1)$ & $36(43.9)$ & 0.414 & $82(30.8)$ \\
\hline \multicolumn{5}{|l|}{ Number of teeth } \\
\hline $\begin{array}{l}\text { Less than } 10 \\
\text { More than } 10\end{array}$ & $\begin{array}{c}101(63.9) \\
58(53.7)\end{array}$ & $\begin{array}{l}57(36.1) \\
50(46.3)\end{array}$ & 0.095 & $\begin{array}{l}158(59.4) \\
108(40.6)\end{array}$ \\
\hline $\begin{array}{c}\text { Satisfaction with chewing } \\
\text { Yes } \\
\text { No } \\
\end{array}$ & $\begin{array}{l}78(56.1) \\
81(63.8)\end{array}$ & $\begin{array}{l}61(43.9) \\
46(36.2)\end{array}$ & 0.203 & $\begin{array}{l}139(52.3) \\
127(47.7)\end{array}$ \\
\hline $\begin{array}{l}\text { Satisfaction with appearance of teeth } \\
\text { Yes } \\
\text { No } \\
\end{array}$ & $\begin{array}{l}85(61.6) \\
74(57.8)\end{array}$ & $\begin{array}{l}53(38.4) \\
54(42.2)\end{array}$ & 0.530 & $\begin{array}{l}138(51.9) \\
128(48.1)\end{array}$ \\
\hline Altered triglycerides & $130(83.3)$ & $26(16.7)$ & $<0.001$ & $156(58.6)$ \\
\hline High blood pressure & $154(65.0)$ & $83(35.0)$ & $<0.001$ & $237(89.1)$ \\
\hline Glucose intolerance & $80(85.1)$ & $14(14.9)$ & $<0.001$ & $94(35.3)$ \\
\hline High hip/waist ratio & $94(87.9)$ & $13(12.1)$ & $<0.001$ & $107(40.2)$ \\
\hline Low HDL cholesterol & $132(83.0)$ & $27(17.0)$ & $<0.001$ & $159(59.8)$ \\
\hline BMI & $30.1 \pm 10.20$ & $26.7 \pm 4.71$ & $=0.002$ & \\
\hline
\end{tabular}

Percentage refers to the total of each line; significance was calculated by Student's t-test for age and chi-square test for the other parameters.

Individuals with the syndrome presented a mean body mass index (BMI) of 30.1, while the elderly without the syndrome had a mean BMI of 26.7 .

Obese individuals (BMI> $30 \mathrm{~kg} / \mathrm{m}^{2}$ ) had the highest prevalence among the elderly with less than 10 teeth, while the group with normal BMI $\left(<25 \mathrm{~kg} / \mathrm{m}^{2}\right)$ had the lowest prevalence in this dental group. However, the chi-square test of the distribution of obesity levels and dental group was not significant $(p=0.408)$. 


\section{Results of the Evaluation on the Risk of Presenting Metabolic Syndrome}

Logistic regression was used to calculate the risk associated with MS in relation to dental evaluation parameters. These parameters mean that individuals have less than 10 teeth, upper total prosthesis, lower total prosthesis, upper partial prosthesis, and lower partial prosthesis, for both sexes and for each sex independently, according to Chart 2.

Chart 2. Likelihood ratio and $95 \%$ confidence interval of the dental evaluation parameters in relation to metabolic syndrome, for both sexes and separately for each sex

\begin{tabular}{|c|c|c|c|}
\hline & & \multicolumn{2}{|c|}{ Both sexes } \\
\hline & LR & 95\%CI & $\mathbf{P}$ \\
\hline Less than 10 teeth & 1.826 & $0.831-4.011$ & 0.134 \\
\hline Upper total prosthesis & 0.715 & $0.290-1.764$ & 0.466 \\
\hline Lower total prosthesis & 1.380 & $0.661-2.879$ & 0.391 \\
\hline Upper partial prosthesis & 1.230 & $0.580-2.609$ & 0.589 \\
\hline \multirow[t]{2}{*}{ Lower partial prosthesis } & 0.874 & $0.474-1.612$ & 0.666 \\
\hline & & \multicolumn{2}{|c|}{ Female sex } \\
\hline Less than 10 teeth & 4.962 & $1.314-18.734$ & 0.018 \\
\hline Upper total prosthesis & 0.308 & $0.074-1.284$ & 0.106 \\
\hline Lower total prosthesis & 1.815 & $0.715-4.609$ & 0.210 \\
\hline Upper partial prosthesis & 1.399 & $0.525-3.733$ & 0.502 \\
\hline \multirow[t]{2}{*}{ Lower partial prosthesis } & 0.905 & $0.427-1.919$ & 0.794 \\
\hline & & \multicolumn{2}{|c|}{ Male sex } \\
\hline Less than 10 teeth & 0.717 & $0.220-2.335$ & 0.581 \\
\hline Upper total prosthesis & 0.645 & $0.148-2.816$ & 0.560 \\
\hline Lower total prosthesis & 1.279 & $0.309-5.302$ & 0.734 \\
\hline Upper partial prosthesis & 1.123 & $0.321-3.934$ & 0.856 \\
\hline Lower partial prosthesis & 0.700 & $0.222-2.214$ & 0.544 \\
\hline
\end{tabular}

LR = likelihood ratio, 95\%CI = 95\% confidence interval.

None of the dental parameters was significant in the logistic regression analysis when both sexes were analyzed together. The probability of MS was only significant when the female sex was evaluated separately and only for the classification of number of teeth. This association remained significant for the female sex even when removing other dental factors. In the interpretation of the logistic regression, having less than 10 natural teeth was a risk factor for MS even when adjusting for the use of dental prosthesis $(p=0.040)$. The risk of MS for people with less than 10 teeth was $31 \%$ higher than for people with more than 10 teeth.

Regarding the use of prostheses, none of them was significant for total prostheses. This means that wearing a prosthesis may not help to prevent MS.

The satisfaction with chewing as a predictor of MS for men and women was not significant. The same may be said about the appearance of teeth.

\section{DISCUSSION}

Tooth loss and edentulism are among the main oral changes found in the elderly ${ }^{15}$. Tooth loss is one of the causes of negative impact on the general oral health and quality of life of individuals, causing chewing impairment and affecting food selection, dietary quality, and nutritional contribution, which may increase the risk of various systemic diseases and 
contribute to weight changes ${ }^{16}$. Overweight and aging are some of the risk factors of the metabolic syndrome (MS) ${ }^{17}$.

The main findings of the present study show a significantly increased risk for elderly women to have MS, with high prevalence of tooth loss, highlighting the importance to preserve and maintain the natural dentition. This study suggests that maintaining the natural dentition is important for elderly women as a protective factor for the development of MS. This is also essential among the elderly population, considering it relates directly to an increase in mortality rates due to cardiovascular events ${ }^{15,18}$. However, it is worth noting that the results of the present study do not confirm that natural dentition is a protective factor for the development of MS in non-elderly individuals.

The results of this study are similar to those presented by Lu et al. ${ }^{19}$ who, when evaluating 97,098 participants from all 31 provinces of mainland China, observed that the prevalence of MS in women was significantly higher than in men. However, the results of the studies by O'Neill, $0^{\prime}$ Driscoll ${ }^{7}$ show that MS prevalence increases with age, but with no significant difference between sexes.

There is no agreement in the literature about the prevalence between sexes. Lee et al. ${ }^{20}$ found a relationship between MS and sex, confirming that women presented more combinations of MS components than men. The main sex differences observed in their study were as follows: higher prevalence of abdominal obesity and low HDL-C in women than in men and a greater prevalence of high triglycerides level, high blood pressure, and high glucose levels in men than in women. Sex differences in the components of MS contributed to the diagnosis. Moore et al. ${ }^{21}$ affirm that the syndrome is more associated with age group than with sex, which suggests that, given the demographic trend of increasing age in the US population, further increases in MS prevalence are expected with concomitant escalations in related chronic diseases and conditions.

In this study, having more than 10 natural teeth in the oral cavity was a protective factor for MS and patients with more than 10 teeth had a lower risk of MS. Additionally, being a woman and having less than 10 teeth in the oral cavity were risks for developing MS. Studies have shown a relationship among tooth loss and obesity, nutritional deficit, hypertension, cognitive dysfunction, and higher mortality risk ${ }^{16}$. Oral health measured by tooth loss is associated with negative impacts on general quality of life ${ }^{22}$.

Regarding men, the result was not significant for the number of teeth, which is not a predictor of MS in this sex. This study actively sought elderly participants of both sexes, but the greater presence of women may have influenced the result obtained.

Several factors may be related to tooth loss, among which periodontitis is one of the main causes $^{12}$. Studies have investigated the existence of the influence of periodontitis on the development of MS. The migration of oral bacteria and their by-products to the circulatory system, with systemic dissemination of local inflammatory mediators, such as interleukins and tumor necrosis factor, may determine a chronic systemic inflammatory condition. Another possibility investigated is that periodontitis might stimulate hepatocytes to produce cytokines in larger amounts, such as C-reactive protein. Thus, the increased production of such circulating metabolites may be related to the causative process of the syndrome ${ }^{18,23}$.

A study by Nascimento et al. ${ }^{24}$ aiming to observe a potential association between periodontal disease and MS results from the structural equation models confirmed the association between MS and periodontitis when both were treated as latent variables in analytical models. Factor analyses revealed that periodontitis comprised two dimensions called "initial" and "advanced" periodontitis. While MS was positively associated with advanced periodontitis, no association was observed between MS and initial periodontitis.

Nutritional status plays an important role in the quality of life and health of the population. Obesity was determined as a nutritional disorder associated with a high incidence of chronic 
non-communicable diseases such as cardiovascular diseases and diabetes, affecting the morbidity and mortality profile of populations. In this context, the anthropometric measurements are the tools mostly used for assessing the nutritional status of the elderly, highlighting the body mass index (BMI) and waist/hip ratio (WHR) used in this study. The BMI is a simple method used to calculate the prevalence of overweight and obesity in the population and the WHR is the best measure of both intra-abdominal fat mass and total fat. However, the BMI may be misleading in individuals with a high rate of lean muscle mass. The WHR is a more accurate measure of body fat distribution and it has been more strongly associated with morbidity and mortality 25 .

In the study with elderly people from Porto Alegre, the results of these measurements were altered and the BMI of most elderly people resulted in overweight or obese patients. The relationship between obesity and hypertension is also stronger and more prevalent in the presence of abdominal obesity. Thus, central obesity is considered a higher prevalence factor for MS in the elderly. According to Brussler et al. ${ }^{6}$, the abdominal accumulation of body fat predicts metabolic disorders that structure MS. A subclinical inflammatory state is among the characteristics of MS and it is evaluated usually by determining the serum concentration of the C-reactive protein that increases in obesity, predicting a cardiovascular event.

The results hereby obtained reinforce the idea of an important association between MS and oral health, especially in women with reduced numbers of teeth.

Although the number of teeth is important to determine a functional dentition, evaluating the distribution of teeth in the dental arches is also imperative, especially when the individual does not wear a dental prosthesis. In addition, the presence of teeth does not mean that it is functional, because the presence of caries and periodontitis compromise function. These factors were not evaluated in the present study, which represents a limitation, establishing potential topics for further research.

\section{CONCLUSION}

The findings of the present study support the hypothesis that the oral health of the individuals analyzed, expressed by the number of teeth, may compromise and increase the risk of metabolic syndrome (MS) in elderly women. Although MS is important for being represented by the aggregation of predisposing factors for the development of cardiovascular diseases and diabetes, there is a lack of data on the characteristics and determinants of this disease in the Brazilian population.

\section{REFERENCES}

1. Sinha N, Bhattacharya A, Deshmukh PR, Panja TK, Yasmin S, Arlappa N. Metabolic syndrome among elderly care-home residents in southern India: a cross-sectional study. WHO South-East Asia J Public Health. 2016 Apr;5(1):62-9. http://dx.doi.org/10.4103/2224-3151.206556. PMid:28604400.

2. Instituto Brasileiro de Geografia e Estatística - IBGE. Síntese de indicadores sociais: uma análise das condições de vida da população brasileira 2016. Rio de Janeiro: IBGE; 2016.

3. Khosravi-Boroujeni H, Ahmed F, Sadeghi M, Roohafza H, Talaei M, Dianatkhah M, et al. Does the impact of metabolic syndrome on cardiovascular events vary by using different definitions? BMC Public Health. 2015 Dec;15(1):1-8. http://dx.doi.org/10.1186/s12889-015-2623-3. PMid:26715355.

4. Martin K, Mani M, Mani A. New targets to treat obesity and the metabolic syndrome. Eur J Pharmacol. 2015 Sep 15;763(Pt A):64-74. http://dx.doi.org/10.1016/j.ejphar.2015.03.093. 
5. Grundy SM. Overnutrition, ectopic lipid and the metabolic syndrome. J Investig Med. 2016 Aug;64(6):1082-6. http://dx.doi.org/10.1136/jim-2016-000155. PMid:27194746.

6. Bussler S, Penke M, Flemming G, Elhassan YS, Kratzsch J, Sergeyev E, et al. Novel insights in the metabolic syndrome in childhood and adolescence. Horm Res Paediatr. 2017;88(3-4):181-93. http://dx.doi.org/10.1159/000479510. PMid:28848168.

7. O'Neill S, O'Driscoll L. Metabolic syndrome: a closer look at the growing epidemic and its associated pathologies. Obes Rev. 2015 Jan;16(1):1-12. http://dx.doi.org/10.1111/obr.12229. PMid:25407540.

8. Fruh SM. Obesity: risk factors, complications, and strategies for sustainable long-term weight management. J Am Assoc Nurse Pract. 2017 Oct;29(S1):S3-14. http://dx.doi.org/10.1002/23276924.12510. PMid:29024553.

9. Gobato AO, Vasques ACJ, Zambon MP, Barros-Filho AA, Hessel G. Metabolic syndrome and insulin resistance in obese adolescents. Rev Paul Pediatr. 2014 Mar;32(1):55-62. http://dx.doi.org/10.1590/S0103-05822014000100010. PMid:24676191.

10. Festi D, Schiumerini R, Eusebi LH, Marasco G, Taddia M, Colecchia A. Gut microbiota and metabolic syndrome. World J Gastroenterol. 2014 Nov;20(43):16079-94. http://dx.doi.org/10.3748/wjg.v20.i43.16079. PMid:25473159.

11. Gil-Montoya JA, de Mello AL, Barrios R, Gonzalez-Moles MA, Bravo M. Oral health in the elderly patient and its impact on general well-being: a nonsystematic review. Clin Interv Aging. 2015 Feb;10:461-7. http://dx.doi.org/10.2147/CIA.S54630. PMid:25709420.

12. Tyrovolas S, Koyanagi A, Panagiotakos DB, Haro JM, Kassebaum NJ, Chrepa V, et al. Population prevalence of edentulism and its association with depression and self-rated health. Sci Rep. 2016 Nov;6(1):1-9. http://dx.doi.org/10.1038/srep37083. PMid:27853193.

13. Nibali L, Tatarakis N, Needleman I, Tu YK, D’Aiuto F, Rizzo M, et al. Clinical review: association between metabolic syndrome and periodontitis: a systematic review and meta-analysis. J Clin Endocrinol Metab. 2013 Mar;98(3):913-20. http://dx.doi.org/10.1210/jc.2012-3552. PMid:23386648.

14. Alhabashneh R, Khader Y, Herra Z, Asa'ad F, Assad F. The association between periodontal disease and metabolic syndrome among outpatients with diabetes in Jordan. J Diabetes Metab Disord. 2015 Aug 16;14:67. http://dx.doi.org/10.1186/s40200-015-0192-8. PMCID: PMC4537782.

15. Tsai SJ, Lin MS, Chiu WN, Jane SW, Tu LT, Chen MY. Factors associated with having less than 20 natural teeth in rural adults: a cross-sectional study. BMC Oral Health. 2015 Dec;15(1):158. http://dx.doi.org/10.1186/s12903-015-0147-y. PMid:26654530.

16. Friedman PK, Lamster IB. Tooth loss as a predictor of shortened longevity: exploring the hypothesis. Periodontol 2000. 2016 Oct;72(1):142-52. http://dx.doi.org/10.1111/prd.12128. PMid:27501497.

17. Ju SY, Lee JY, Kim DH. Association of metabolic syndrome and its components with all-cause and cardiovascular mortality in the elderly: a meta-analysis of prospective cohort studies. Medicine. 2017 Nov;96(45):e8491. http://dx.doi.org/10.1097/MD.0000000000008491. PMid:29137039.

18. Carramolino-Cuéllar E, Tomás I, Jiménez-Soriano Y. Relationship between the oral cavity and cardiovascular diseases and metabolic syndrome. Med Oral Patol Oral Cir Bucal. 2014 May;19(3):e28994. http://dx.doi.org/10.4317/medoral.19563. PMid:24121926.

19. Lu J, Wang L, Li M, Xu Y, Jiang Y, Wang W, et al. Metabolic syndrome among adults in China: the 2010 China noncommunicable disease surveillance. J Clin Endocrinol Metab. 2017 Feb;102(2):507-15. http://dx.doi.org/10.1210/jc.2016-2477. PMid:27898293.

20. Lee S, Ko Y, Kwak C, Yim ES. Gender differences in metabolic syndrome components among the Korean 66-year-old population with metabolic syndrome. BMC Geriatr. 2016 Jan;16(1):27. http://dx.doi.org/10.1186/s12877-016-0202-9. PMid:26803469. 
21. Moore JX, Chaudhary N, Akinyemiju T. Metabolic syndrome prevalence by race/ethnicity and sex in the united states, national health and nutrition examination survey, 1988-2012. Prev Chronic Dis. 2017 Mar;14:1-16. http://dx.doi.org/10.5888/pcd14.160287. PMid:28301314.

22. Haag DG, Peres KG, Brennan DS. Tooth loss and general quality of life in dentate adults from Southern Brazil. Qual Life Res. 2017 Oct;26(10):2647-57. http://dx.doi.org/10.1007/s11136-017-1587-4. PMid:28484913.

23. Lamster IB, Pagan M. Periodontal disease and the metabolic syndrome. Int Dent J. 2017 Apr;67(2):6777. http://dx.doi.org/10.1111/idj.12264. PMid:27861820.

24. Nascimento GG, Leite FRM, Peres KG, Demarco FF, Corrêa MB, Peres MA. Metabolic syndrome and periodontitis: a structural equation modeling approach. J Periodontol. 2019 Jun;90(6):655-62. http://dx.doi.org/10.1002/JPER.18-0483. PMid:30447085.

25. Awasthi A, Rao CR, Hegde DS, Rao NK. Association between type 2 diabetes mellitus and anthropometric measurements - a case control study in South India. J Prev Med Hyg. 2017 Mar;58(1):E56-62. PMid:28515633.

\section{CONFLICTS OF INTERESTS}

The authors declare no conflicts of interest

\section{*CORRESPONDING AUTHOR}

João Paulo De Carli, UPF - Universidade de Passo Fundo, Departamento de Odontologia, 99052-900 Passo Fundo - RS, Brasil, e-mail: joaodecarli@upf.br

Received: March 9, 2019

Accepted: August 5, 2019 